\title{
Pyrimidine-5'-Nucleotidase Deficiency
}

National Cancer Institute

\section{Source}

National Cancer Institute. Pyrimidine-5'-Nucleotidase Deficiency. NCI Thesaurus. Code C131649.

An autosomal recessive disorder caused by mutation of the NT5C3A gene. It is the most frequent abnormality of red cell nucleotide metabolism, causing chronic, non-spherocytic hemolytic anemia. Most affected individuals have Mediterranean, Jewish, or African ancestry. Basophilic stippling and accumulation of pyrimidines within erythrocytes are hallmarks of this disorder. 